\title{
Metabolically Active Prokaryotes and Actively Transcribed Antibiotic Resistance Genes in Sewer Systems: Implications for Public Health and Microbially Induced Corrosion
}

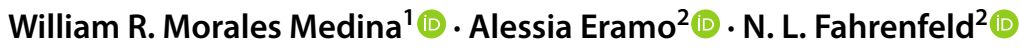

Received: 23 December 2020 / Accepted: 13 May 2021 / Published online: 11 June 2021

(c) The Author(s), under exclusive licence to Springer Science+Business Media, LLC, part of Springer Nature 2021

\begin{abstract}
Sewer systems are reservoirs of pathogens and bacteria carrying antibiotic resistance genes (ARGs). However, most recent high-throughput studies rely on DNA-based techniques that cannot provide information on the physiological state of the cells nor expression of ARGs. In this study, wastewater and sewer sediment samples were collected from combined and separate sanitary sewer systems. The metabolically active prokaryote community was evaluated using 16S rRNA amplicon sequencing and actively transcribed ARG abundance was measured using mRNA RT-qPCR. Three $\left(\operatorname{sul} 1, b l a_{\mathrm{TEM}}, \operatorname{tet}(\mathrm{G})\right)$ of the eight tested ARGs were quantifiable in select samples. Sewer sediment samples had greater abundance of actively transcribed ARGs compared to wastewater. Microbiome analysis showed the presence of metabolically active family taxa that contain clinically relevant pathogens (Pseudomonadaceae, Enterobacteraceae, Streptococcaceae, Arcobacteraceae, and Clostridiaceae) and corrosion-causing prokaryotes (Desulfobulbaceae and Desulfovibrionaceae) in both matrices. Spirochaetaceae and methanogens were more common in the sediment matrix while Mycobacteraceae were more common in wastewater. The microbiome obtained from $16 \mathrm{~S}$ rRNA sequencing had a significantly different structure from the 16S rRNA gene microbiome. Overall, this study demonstrates active transcription of ARGs in sewer systems and provides insight into the abundance and physiological state of taxa of interest in the different sewer matrices and sewer types relevant for wastewater-based epidemiology, corrosion, and understanding the hazard posed by different matrices during sewer overflows.
\end{abstract}

Keywords Antibiotic resistance gene transcripts $\cdot 16 \mathrm{~S}$ rRNA sequencing $\cdot$ Sewer microbiome $\cdot$ Wastewater-based epidemiology $\cdot$ Sewer resistome

\section{Introduction}

Antibiotic-resistant infections are the cause of more than 35,000 deaths a year and the US Centers for Disease Control (CDC) has classified antibiotic resistance as one of the biggest public heath challenges of our time [1]. Sewer systems have been shown to be a potential environmental hotspot for the proliferation of bacteria carrying antibiotic resistance genes (ARGs) and potential human pathogens [2-7].

N. L. Fahrenfeld

nfahrenf@rutgers.edu

1 Microbiology \& Molecular Genetics, Rutgers, The State University of New Jersey, 500 Bartholomew Dr, Piscataway, NJ 08854, USA

2 Civil \& Environmental Engineering, Rutgers, The State University of New Jersey, 500 Bartholomew Dr, Piscataway, NJ 08854, USA
However, most of these studies have been limited to genomic DNA-based analysis that cannot measure gene expression nor discriminate between living cells and DNA from nonliving cells (unless further steps are taken such as PMAPCR or stable isotope probing). Given the public health risk posed by sewer overflows from combined and separate sanitary systems $[8,9]$, a comprehensive assessment of the metabolically active prokaryote community and the occurrence of bacteria capable of expressing antibiotic resistance is warranted. Moreover, having a quantitative measurement of ARG expression and the metabolically active microbiome may help us to understand the selection for specific mechanisms of antibiotic resistance and the loading of active human pathogens in the microbiome during sewer overflow events. Furthermore, the current boom in wastewater-based epidemiology to address SARS-CoV-2 has demonstrated the utility of sewage monitoring and understanding in-sewer 
processes potentially impacting the microbiome could improve our ability to interpret sewer epidemiology data.

A previous study in our lab evaluated the abundance of selected ARGs via qPCR and the prokaryotic community in metagenomic DNA from combined and separate sanitary sewer sediment and wastewater samples [5]. The results showed the presence of all the tested ARGs with variation by season and matrix ranging from 0.8 to 11 $\log _{10}$ ARG copies per 16S rRNA gene copy and also the presence of bacterial taxa containing potential human pathogens and corrosion-causing prokaryotes [5]. This study aims to reassess the abundance of ARGs and the microbial community composition from selected sampled of this previous study [5] but at the actively transcribed, RNA level. The presence of specific mRNA sequences in environmental total RNA samples indicates that some bacterial cells have the required genetic code to transcribe a gene and potentially express it. Therefore, targeting mRNA molecules transcribed from ARGs through RTqPCR can provide quantitative information on whether specific ARGs are being transcribed in the bacterial population.

Because only metabolically active cells can synthesize rRNA, assessing the microbial diversity through $16 \mathrm{~S}$ rRNA sequencing (i.e., sequencing of cDNA from rRNA) rather than the $16 \mathrm{~S}$ rRNA gene sequencing provides information about the physiological state of the source of the sequences. In addition, due to the short half-life of RNA molecules relative to DNA [10], 16S rRNA transcript sequencing can also be used as a tool to reduce the signal from extracellular and dead cells' rRNA in 16S rRNA gene sequencing for microbiome studies. Therefore, a sewer microbiome assessment using 16S rRNA sequencing can provide information about the physiological state of taxa of interest within the sewer microbiome. This approach has been previously used to study the metabolically active microbiome of some environmental matrices including tap water, freshwater, hydrate ecosystems, deep ocean sediments, Antarctic coastal waters, and coral reefs [10-14], but to our knowledge, this has not been used to evaluate the metabolically active prokaryotic diversity in sewer system matrices. Transcriptomic analysis of ARGs using mRNA RT-PCR has been reported in clinical isolates $[15,16]$.

The specific aims of this study were to (1) characterize, quantify, and compare the occurrence of actively transcribed ARGs in wastewater and sewer sediment of combined and separate sanitary sewer systems; (2) describe the metabolically active prokaryotic diversity in both sewer matrices and sewer types, focusing on taxonomical families containing potential human pathogens and corrosion-causing prokaryotes; and (3) compare the sewer sediment and wastewater microbiome obtained by $16 \mathrm{~S}$ rRNA and 16S rRNA gene sequencing, using the 16S rRNA gene sequencing data from our previous study [5]. To achieve these aims, sewer sediment and wastewater samples were collected from separate sanitary and combined sewer systems. mRNA was purified from the total RNA, and RTqPCR was used to detect and quantify selected actively transcribed ARGs. cDNA was synthesized from the total RNA and the 16S rRNA was further sequenced in order to study the prokaryotic diversity of metabolically active cells. These results can provide insight on the abundance of actively transcribed ARGs and the persistence of metabolically active microbial groups of clinical relevance, both of which may present a public health risk during sewer overflow events.

\section{Methods}

\section{Sewer Sediment and Wastewater Sampling}

Wastewater influent and sewer sediment samples were collected from five different combined and separate sanitary sewer systems (Table 1). Samples were collected between

Table 1 Information about the sewer type, sampling date, and location of the samples

\begin{tabular}{llll}
\hline Systems ID & Sewer type & $\begin{array}{l}\text { Sampling date (air tempera- } \\
\left.\text { ture in }{ }^{\circ} \mathrm{C}\right)\end{array}$ & Sediment sampling location \\
\hline $\mathrm{C} 1$ & Combined & $6 / 28 / 17(25)$ & Sediment deposits from bottom of sewer pipe collected via manhole \\
& & \\
C2 & Combined & $7 / 13 / 17(28)$ & Sediment deposits from bottom of sewer pipe collected via manhole \\
& & & \\
C3 & Combined & $6 / 26 / 17(28)$ & Sewer sediment discharged during CSO events and stockpiled in \\
& & $7 / 11 / 17(32)$ & CSO detention tank \\
S1 & Separate & $6 / 29 / 17(24)$ & Sediment deposits from pump or metering stations \\
& & $7 / 5 / 17(27)$ & Wet well \\
S2 & Separate & $9 / 28 / 17(29)$ & \\
& &
\end{tabular}


June and September 2017 in replicate at least one week apart with a total of 20 samples ( 5 systems $\times 2$ matrices $\times 2$ replicates) during baseflow conditions with precipitation measurements in the preceding $48 \mathrm{~h}$ at the nearest gauges averaging $0.38 \pm 0.50 \mathrm{~cm}$ (ranging from 0 to $1.32 \mathrm{~cm}$ ). All the samples used in this study represent a subset of those used for DNA analyses in previously published research from our lab [5]. The locations for sewer sediment grab samples were selected based on the presence of solid deposition sufficient to collect $1 \mathrm{~L}$ including manholes and wet wells. Samples collected from the five different sewer systems were labeled as $\mathrm{C} 1, \mathrm{C} 2$, and $\mathrm{C} 3$ for the three combined sewer systems, and S1 and S2 for the separate sanitary sewer systems. Composite wastewater influent samples ( $24 \mathrm{~h}, 2 \mathrm{~L}$ via autosampler) were collected on the same day of each sediment sampling event from the corresponding downstream wastewater treatment plant (WWTP). More details of the sampling events and locations can be found in Table 1 and in Eramo et al. [5].

To preserve the total RNA from the samples, approximately $2 \mathrm{~g}$ of sediment was transferred to a $15-\mathrm{mL}$ Falcon tube containing $6 \mathrm{~mL}$ of LifeGuard ${ }^{\mathrm{TM}}$ Soil preservation solution (Qiagen, Germantown, MD) in the field, transported to the lab inside a cooler with ice, then stored at $4{ }^{\circ} \mathrm{C}$. For wastewater samples, samples were transported to the lab inside a cooler with ice and the prokaryotic cells were immediately concentrated by filtering $\sim 150 \mathrm{~mL}$ of wastewater through $0.22-\mu \mathrm{m}$ nitrocellulose filters (Millipore Corporation, Billerica, MA). The filter membrane containing the cells was placed in a $15-\mathrm{mL}$ Falcon tube containing $3 \mathrm{~mL}$ of LifeGuard ${ }^{\mathrm{TM}}$ Soil preservation solution and then stored at $4{ }^{\circ} \mathrm{C}$.

\section{Biomolecular Analysis}

RNA was extracted from all samples and field blanks for cDNA synthesis followed by qPCR and amplicon sequencing of the $16 \mathrm{~S}$ rRNA gene. The preserved sediment and wastewater samples stored in $15-\mathrm{mL}$ tubes with LifeGuard ${ }^{\mathrm{TM}}$ Soil preservation solution were centrifuged at $4000 \times \mathrm{g}$ for $10 \mathrm{~min}$; then, the supernatant containing the preservation solution was discarded. For the sewer sediment samples, $0.5 \mathrm{~g}$ (wet weight) was added to the RNA-lysing tubes, and for wastewater samples, the filter membrane was transferred to the RNA lysing tubes. Total RNA was extracted using the RNeasy PowerSoil Total RNA Kit (Qiagen, Germantown, MD) following the manufacturer's directions, followed by a DNA clean up with DNase Max Kit (Qiagen, Germantown, MD). The absence of DNA contamination in the total RNA was confirmed by PCR targeting the bacterial 16S rRNA gene in the RNA samples (without adding reverse transcriptase to the PCR mix) using the primers and protocol [17] listed in
Table S1. Visualization of PCR products was done using gel electrophoresis (note: no bands were observed except in positive controls, indicating there was not DNA contamination of the samples). The total RNA was quantified using a Nanodrop, then an aliquot from each sample was used to synthesize cDNA using the SuperScript IV VILO Mastermix with ezDNase (Invitrogen, Waltham, MA) following the manufacturer's directions. Another aliquot of the total RNA from each sample was used to purify the mRNA using the MICROBExpress Bacterial mRNA Purification kit (Invitrogen, Waltham, MA) following the manufacturer's directions. To confirm that there was no contamination from DNA in the purified mRNA, PCR targeting the bacterial 16S rRNA gene was performed as previously explained. Then, the cDNA encoded from the purified mRNA was synthesized as previously explained. The mRNA purification procedure was performed on 14 of the 20 samples. The other 6 samples had a lower total RNA concentration than the minimum required for the purification procedure $(<0.07 \mu \mathrm{g} / \mu \mathrm{L})$. Five of these unprocessed samples were wastewater samples while only one was a sediment sample. Previously, total DNA was extracted for qPCR and amplicon sequencing [5], allowing for comparison.

qPCR targeting selected ARGs $(\operatorname{sul1}[18], \operatorname{tet}(\mathrm{G})[19]$, $\operatorname{tet}(\mathrm{W})[20], \operatorname{tet}(\mathrm{O})[20], \operatorname{erm} \mathrm{F}[21], \mathrm{NDM}-1[22], \operatorname{van} \mathrm{A}[23]$, and bla $_{\text {TEM }}[24]$ ) and traditional PCR targeting atpE [25], a functional gene present in non-tuberculous Mycobacterium spp., was performed on the cDNA that was synthesized from the mRNA of each sample. These ARGs encoding for sulfonamide, macrolide, tetracycline, beta-lactam, and vancomycin antibiotic resistance were selected due to their common abundance in sewer system matrices [3-5]. NDM-1 was selected because some bacterial species with this functional gene have been recently classified as an "urgent threat" by the US CDC [1].

qPCR reaction mixtures for $s u l 1, b l a_{\mathrm{TEM}}, \operatorname{tet}(\mathrm{G}) \operatorname{tet}(\mathrm{O})$, $\operatorname{tet}(\mathrm{W}), \operatorname{erm} \mathrm{F}$, and $\operatorname{van} \mathrm{A}$ gene consisted of $5 \mu \mathrm{L}$ of SsoFast Eva Green ${ }^{\circledR}$ SuperMix (BioRad, Hercules, CA), $0.4 \mu \mathrm{M}$ of the forward and reverse primers, $2.4 \mu \mathrm{L}$ of molecular biology-grade water, and $1 \mu \mathrm{L}$ of diluted cDNA from the samples. The reaction mixture of NDM-1 and atpE consisted of $5 \mu \mathrm{L}$ of SsoAdvanced Universal Probes SuperMix (BioRad, Hercules, CA), $0.22 \mu \mathrm{M}$ of the forward and reverse primers, $0.07 \mu \mathrm{M}$ of the probe, $1 \mu \mathrm{L}$ of molecular biology-grade water, and $1 \mu \mathrm{L}$ of diluted cDNA from the samples. qPCR reactions for all the samples were performed in a Real-Time Thermocycler (BioRad CFX96 Touch, Hercules, CA). Thermocycler conditions for each gene are specified in Table S1. All the samples were analyzed in triplicate in order to have technical replication. A standard curve of seven points with a range from $10^{2}$ to $10^{8}$ gene copies and a no-template control (NTC) were also 
run in triplicate in each qPCR plate. The standard curves for each primer set were generated using PCR amplicons obtained from environmental samples and further confirmed by Sanger sequencing (GeneWiz, Piscataway, NJ). Once the sequences were confirmed via NCBI Nucleotide BLAST, the PCR products were cloned with a TOPO A cloning kit (Thermo Fisher, Waltham, WA) following the manufacturer's instructions and quantified using the method described in Pei et al. [18]. The average $R^{2}$ of the standard curves in all reactions was $0.98 \pm 0.01$, and the efficiency was $94.2 \pm 2.8 \%$. These averages do not include the results from $a t p \mathrm{E}$, which were reported as present or absent due to low efficiency. Presence/absence of atpE was confirmed by gel electrophoresis. qPCR results of the ARGs were presented as gene copies per gram of cDNA based on the DNA concentration in the samples that was measured using a NanoDrop One (Thermo Fisher Scientific, Waltham, MA). The limit of quantitation (LOQ) was determined based on the lowest qPCR standard and ranged from $\log _{10}$ (8.84) to $\log _{10}$ (8.99) gene copies/g of DNA due to the different amount of DNA in different samples. Melt curve analysis was performed on all the SYBR green qPCR reactions. Agarose gel electrophoresis was used to verify the amplicon length of selected qPCR products from all genes and to confirm the presence of genes with concentrations below the LOQ.

To study the prokaryotic diversity of metabolically active microbial groups of interest in sewer systems, 16S rRNA amplicon sequencing (Illumina MiSeq, 300-bp, paired-end, V3-V4 region) was performed to the cDNA samples that were synthesized from the total RNA (referred to throughout the text as $16 \mathrm{~S}$ rRNA sequencing). Sequencing was performed at a commercial laboratory (MrDNA, Shallowater, $\mathrm{TX}$ ) targeting the V3-V4 region on all of the sewer sediment samples $(\mathrm{N}=10)$ and wastewater influent samples $(\mathrm{N}=10)$. The primer sequences used by the commercial lab to generate the 16S rRNA gene amplicons were the following: forward 5'-CCT ACG GGN GGC WGC AG-3' and reverse 5'-GAC TAC HVG GGT ATC TAA TCC-3' [26].

To compare the diversity of ribosome synthesizing cells (16S rRNA sequencing) with the total microbiome based on DNA analysis (16S rRNA gene sequencing), data from a previous amplicon sequencing of the 16S rRNA gene on the total DNA of aliquots of the same sewer sediment $(\mathrm{N}=10)$ and wastewater $(\mathrm{N}=10)$ [5] was re-analyzed (given that it had been analyzed using Qiime rather than Qiime2) and processed along with the $16 \mathrm{~S}$ rRNA sequencing data (as explained below) to facilitate comparison. Note, the $16 \mathrm{~S}$ rRNA gene sequencing results were not significantly different between the different versions of Qiime ( $p=0.30$, PERMANOVA); however, to be consistent, the output for Qiime2 was used for comparisons between the 16S rRNA and 16S rRNA gene sequencing.
Amplicon sequencing results were processed using Qiime2-2019.4 [27] by following the "Atacama soil microbiome" tutorial in https://qiime2.org and a previously published pipeline [28] in order to create operational taxonomic unit (OTU) tables. A median of 20 quality score was used as threshold to truncate low-quality nucleotides. Chimeras were verified using the option "qiime vsearch uchime-denovo." The sequences of all samples including the 16S rRNA and 16S rRNA gene samples were randomly subsampled (rarefied) at 23,000 sequences per sample. Rarefaction curves are shown in Fig. S1. Sequences were submitted to NCBI's Short Read Archive (https://www. ncbi.nlm.nih.gov) and are available under accession numbers SAMN10356374-SAMN10356393. All the sequences including the 16S rRNA gene sequences can be found under the project number PRJNA503259 in NCBI. The RNA to DNA ratio of relevant prokaryote taxa was calculated by dividing each $16 \mathrm{~S}$ rRNA OTU sequence count after rarefaction by the corresponding 16S rRNA gene OTU sequence count after rarefaction and then averaging these values $(\mathrm{N}=2)$.

\section{Microbial Diversity and Statistics}

All statistical and prokaryote diversity analyses were performed in R (http://www.r-project.org) [29]. To compare the abundance of ARGs as a function of matrix (sediment vs. wastewater) and sewer type (combined vs. separate), a Wilcoxon Rank Sum test was performed for non-parametric data and a Student $t$-test for parametric data. Non-normality of the data was confirmed by a Shapiro-Wilk test. To compare the abundance of these genes between the five different collection systems/WWTP, a Kruskal-Wallis test was done with a post hoc pairwise $t$-test with a Bonferroni correction for multiple comparisons.

Alpha-diversity measurements including richness, evenness, Shannon, Simpson, inverse Simpson, and Fisher alpha diversity indices were performed using the Vegan: Community Ecology Package, version 2.5-6 [30]. Differences in diversity indices between samples were determined with a Kruskal-Wallis test followed by a post hoc pairwise $t$-test with a Bonferroni correction. Differences in diversity indices as a function of matrix (sediment vs. wastewater) and sewer type (combined vs. separate) were determined though a Wilcoxon Rank Sum test or a Student $t$-test, as described above. To compare the microbial community structure between matrices (sediment vs. wastewater), sewer type (separate vs. combined), and 16S rRNA gene sequencing (total prokaryotes) vs. 16S rRNA sequencing (Ribosomesynthesizing prokaryotes), a Bray-Curtis dissimilarity matrix was calculated at the family level followed by nonmetric multidimensional scaling (nMDS) [30]. Statistical 
differences were determined through a permutational multivariate analysis of variance (PERMANOVA) [30] and a post hoc pairwise PERMANOVA with a Bonferroni correction (PairwiseAdonis package version 0.3.) [31]. Cluster analysis was performed to compute a dendrogram using a Bray-Curtis dissimilarity index [30]. A heatmap was created [29] to visualize the dominant family taxa in each sample.

\section{Results}

\section{Analysis and Quantification of ARG Transcripts}

To understand the abundance of ARGs being actively transcribed in sewer systems, cDNA synthesized from the mRNA from sewer sediment and wastewater samples were analyzed through qPCR. Three of the eight targeted ARGs $\left(\operatorname{sul} 1, \operatorname{bla}_{T E M}, \operatorname{tet}(\mathrm{G}) \operatorname{tet}(\mathrm{O}), \operatorname{tet}(\mathrm{W}), \operatorname{erm} \mathrm{F}, \operatorname{van} \mathrm{A}\right.$, and NDM1) were detected in select samples $\left(\operatorname{sul} 1, \operatorname{bla}_{T E M}, \operatorname{tet}(\mathrm{G})\right.$, Fig. 1) from the five collection systems/WWTP. No qPCR signal was detected from the other five genes in any of the samples. Of the 14 samples analyzed, 10 were positive for at least one ARG: eight (8/9) were sewer sediment samples and two $(2 / 5)$ were wastewater samples.

Of the three detected ARGs $\left(\operatorname{sul} 1, \operatorname{bla}_{\mathrm{TEM}}\right.$, $\left.\operatorname{tet}(\mathrm{G})\right)$, sul 1 was the most common and was detected in 8 of the 10 samples that were positive for ARGs $(\mathrm{N}=10$, Fig. 1). However, sul 1 was above the limit of quantitation (LOQ) in only two of

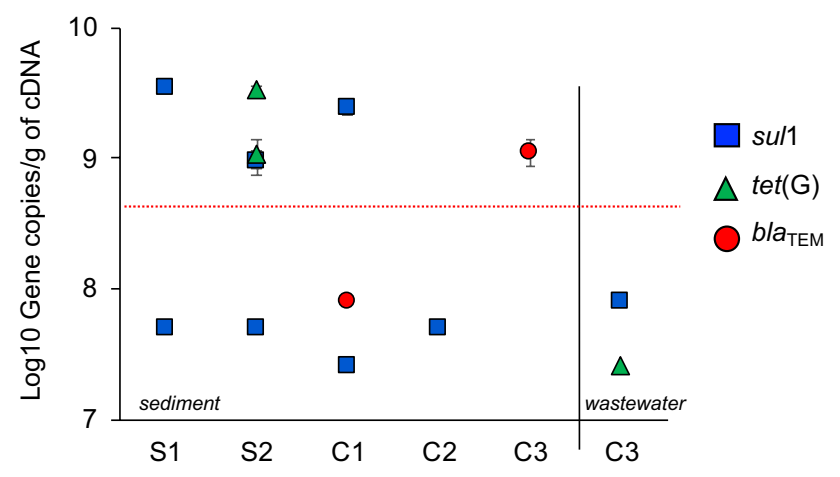

Fig. 1 Abundance of actively transcribed ARGs based on mRNA RT-qPCR in combined (C) and separate (S) sanitary sewer system from sediment and wastewater matrices. Two identical symbols in sewer sediment samples S1, S2, and C1 represent the replicate samples collected on different dates $(n=2)$ Error bars represent the standard deviation of technical replicates $(n=3)$. The range of the LOQ was established based on the qPCR lowest value of the standard curve calculated with the sample that had the highest and lowest cDNA concentration $\left(\log _{10}(8.84)\right.$ to $\log _{10}(8.99)$ gene copies/g of DNA). Points above the dotted lines represent samples above the LOQ. Points below the red dotted line represent the samples that were below the LOQ but detected by traditional PCR. Points below the LOQ were assigned with a random value between $\log _{10} 7.0$ and $\log _{10} 8.0$ the samples. $\operatorname{tet}(\mathrm{G})$ was the second most commonly observed ARG and was detected in 3 of the 10 samples that were positive for ARGs but was above the LOQ in two samples (Fig. 1). bla $a_{\mathrm{TEM}}$ was detected in two sediment samples and above LOQ in one sample (Fig. 1). None of the targeted ARGs were detected above the LOQ in wastewater samples. No differences in ARG transcripts were observed by sewer type $(p=0.12$, PERMANOVA).

\section{Prokaryote Community Analysis}

The diversity of cells actively synthesizing ribosomes was analyzed through $16 \mathrm{~S}$ rRNA amplicon sequencing. No differences in the 16S rRNA sequencing data were detected by comparing the alpha diversity measurements (Table S2) of all the samples as a factor of matrix ( $p>0.34$, paired Wilcoxon Rank Sum test) or as factor of sewer type (separate vs. combined; $p=0.31$, Wilcoxon Rank Sum test). Beta diversity analysis of the community structure of the 16S rRNA sequencing visualized though nMDS resulted in differences as a factor of matrix (sediment vs. wastewater, Fig. S2A; $p=0.048$, PERMANOVA). However, no difference was detected in the same analysis for the rRNA gene sequencing (Fig. S2B; $p=0.60$, PERMANOVA). No differences in the $16 \mathrm{~S}$ rRNA prokaryote community structure (Fig. 2A) were detected between separate and combined sewer systems' samples ( $p=0.12$, PERMANOVA). Cluster analysis of the 16S rRNA data (Fig. 3A) showed that three of the five sediment samples from combined sewers clustered with more than $85 \%$ similarity. Samples C1-Sed, S2-WW, and S2-Sed clustered most similarly with their replicate samples (same system, same matrix), exhibiting similarities over 77\% (Fig. 3A). No other clusters with more than $75 \%$ similarity were observed to be associated with any other factor.

The microbial community structure was compared between actively transcribed $16 \mathrm{~S}$ rRNA and DNA from $16 \mathrm{~S}$ rRNA gene amplicons (Fig. 2B). The 16S rRNA community profile in wastewater samples was significantly different ( $p<0.0060$, pairwise PERMANOVA) from 16S rRNA gene community analysis. This difference is not noticed in sediment samples ( $p>0.060$, pairwise PERMANOVA). In wastewater samples, sequences from the family of Streptococcaceae were significantly higher in the 16S rRNA gene analysis compared to the $16 \mathrm{~S}$ rRNA sequencing (Fig. S3 and Fig. $4, p<0.041$, pairwise $t$-test). However, sequences from other family taxa (not shown in Fig. 4), including taxa containing corrosion-causing prokaryotes and potential human pathogens, were significantly more abundant in the 16S rRNA sequencing analysis than in the 16S rRNA gene sequencing analysis resulting in RNA to DNA ratios above one. For example, the Pseudomonadaceae taxon resulted in a relative sequence abundance of more than $50 \%$ in 8 of the $2016 \mathrm{~S}$ rRNA samples vs. $0.75 \% \pm 0.53 \%$ in the $16 \mathrm{~S}$ rRNA 
A

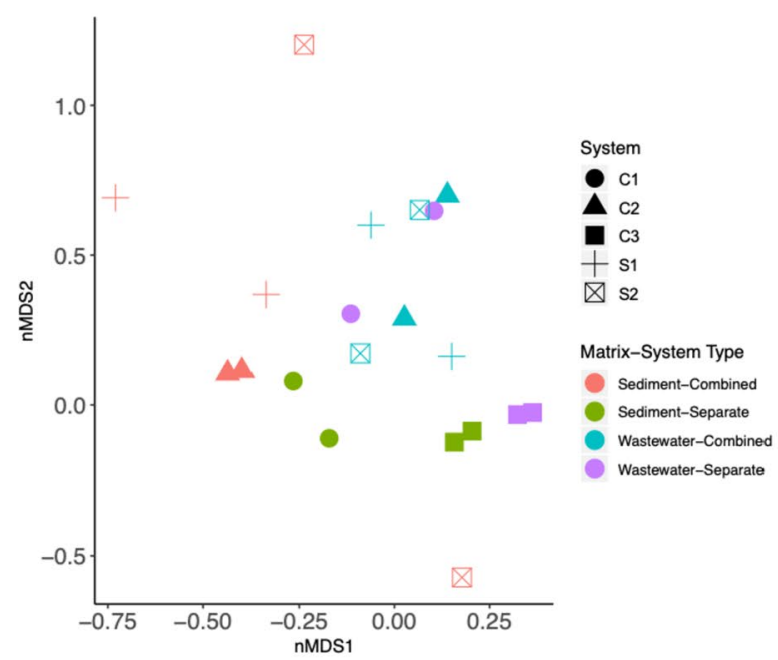

Fig. 2 Non-metric multidimensional scaling (nMDS) showing the A prokaryote community structure based on 16S rRNA analysis (stress $=0.073$ ) as a factor of sewer system (shapes) and matrix-sewer type (color), and $\mathbf{B}$ a comparison between the prokaryote community

gene analysis and with an RNA to DNA ratio above one in 16 of the 20 samples (Fig. S3).

To illustrate the presence of specific metabolically active microbes in sewer systems, a heatmap containing the most abundant prokaryote families of the 16S rRNA sequencing analysis (Fig. 3B). Of the 60 illustrated taxa, two of them belong the Archaea domain and are hydrogenotrophic methanogens: Metanobacteraiacea and Methansaetaceae. The other 58 taxa belong to the bacteria domain and including some environmental bacteria taxa of interest and some of potential clinical relevance. Arcobacteraceae, Pseudomanadaceae, Streptococcaceae, Clostridiaceae, and Enterobacteriaceae which are family taxa containing potential human pathogens were detected metabolically active in both matrices. Some relevant families were more commonly observed in the wastewater than the sediment matrix. This is the case of Mycobacteraceae which was detected in $9 / 10$ of the wastewater samples but only in $2 / 10$ of the sediment samples. Moreover, pathogenic species of non-tuberculosis Mycobacteria (NTM) were detected in gel electrophoresis but not quantifiable by qPCR in the wastewater samples. Other families were more prevalent in the sewer sediment or similar between matrices. Spirochaetaceae, which contains some potential human pathogen species, were mainly found inhabiting the sediment matrix (6/10 samples) rather than in wastewater samples (2/10) (Figs. 3B and 4). In the case of relevant environmental taxa known to be involved in microbially induced corrosion (MIC), methanogenic archaea, 16S rRNA sequences had higher relative abundance in the sediment matrix than in wastewater (Fig. 3B, $p=0.041$, PERMANOVA). Sulfate-reducing bacteria (SRB) taxa, Desulfobulbaceae and
B

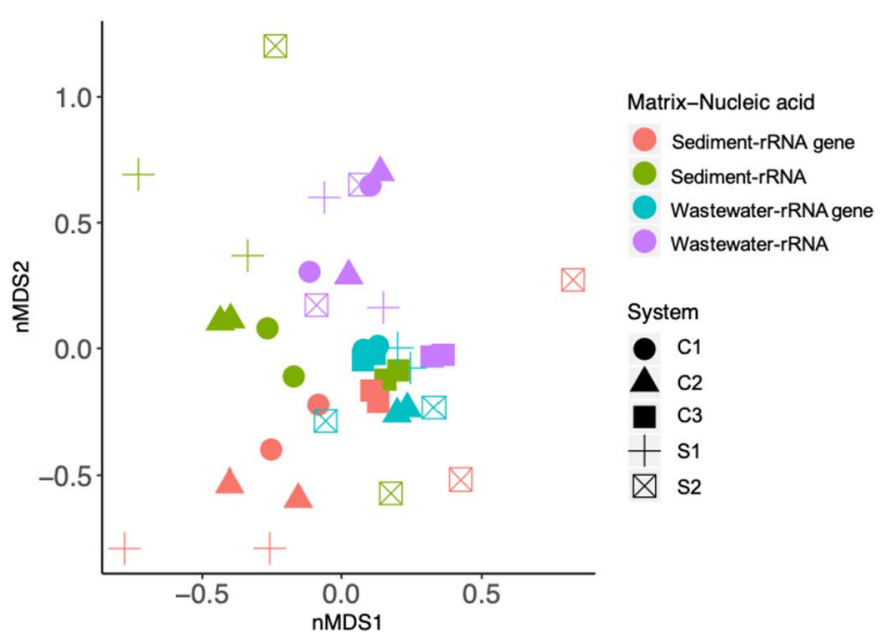

structure obtained from 16S rRNA vs. 16S rRNA gene sequencing (stress $=0.065$ ) as a factor of matrix-starting nucleic acid used for analysis (colors) and sewer system (shapes)

Desulfovibrionaceae, were metabolically active with similar relative abundance of $16 \mathrm{~S}$ rRNA sequences in both matrices (Fig. 3B).

\section{Discussion}

\section{Characterization of ARG Transcripts and Comparison with Previous Study}

sul1 was the most commonly detected ARG transcript in the sewer samples. This has consistently been reported as the most abundant ARG among all matrices in sewer system (wastewater [3-5, 7, 32], sewer sediment [2, 5], and biofilms $[2,7]$ ) including in the paired DNA samples for this study ranging from -1 to $-2 \log 10$ copies per copy of $16 \mathrm{~S}$ rRNA gene [5]. $\operatorname{tet}(\mathrm{G})$ and $b l a_{\text {TEM }}$ have also been commonly detected in sewer bacterial communities [2-5, 7, 32, 33]. tet $(\mathrm{G})$ ranged between -2 and $-3.5 \log 10$ copies per copy of $16 \mathrm{~S}$ rRNA gene. However, ermF, the second most abundant gene in the paired DNA samples ( -2 to -3 Log 10 copies per copy of $16 \mathrm{~S}$ rRNA gene) [5], was not detected as actively transcribed in the mRNA. This suggests that abundance of an ARG at the metagenomic level (total DNA) does not necessary correlate with abundance of the actively transcribed gene (mRNA). The low abundance of transcribed ARGs may also suggest that even though genomic studies have highlighted sewer systems as hotspots of ARGs [2, 4, 5, 7, 9], the proliferation of ARGs do not scale linearly with the proliferation 
Fig. 3 Beta-diversity analysis of the microbiomes of combined (C) and separate (S) sanitary sewer wastewater (WW) and sediment (Sed) matrices. A A cluster analysis illustrating the percent similarity between each sample. B a heatmap showing the microbiome at the family level of the samples. Red corresponds to a higher relative abundance of sequences corresponding to the taxon while yellow corresponds to a lower number of sequences
A
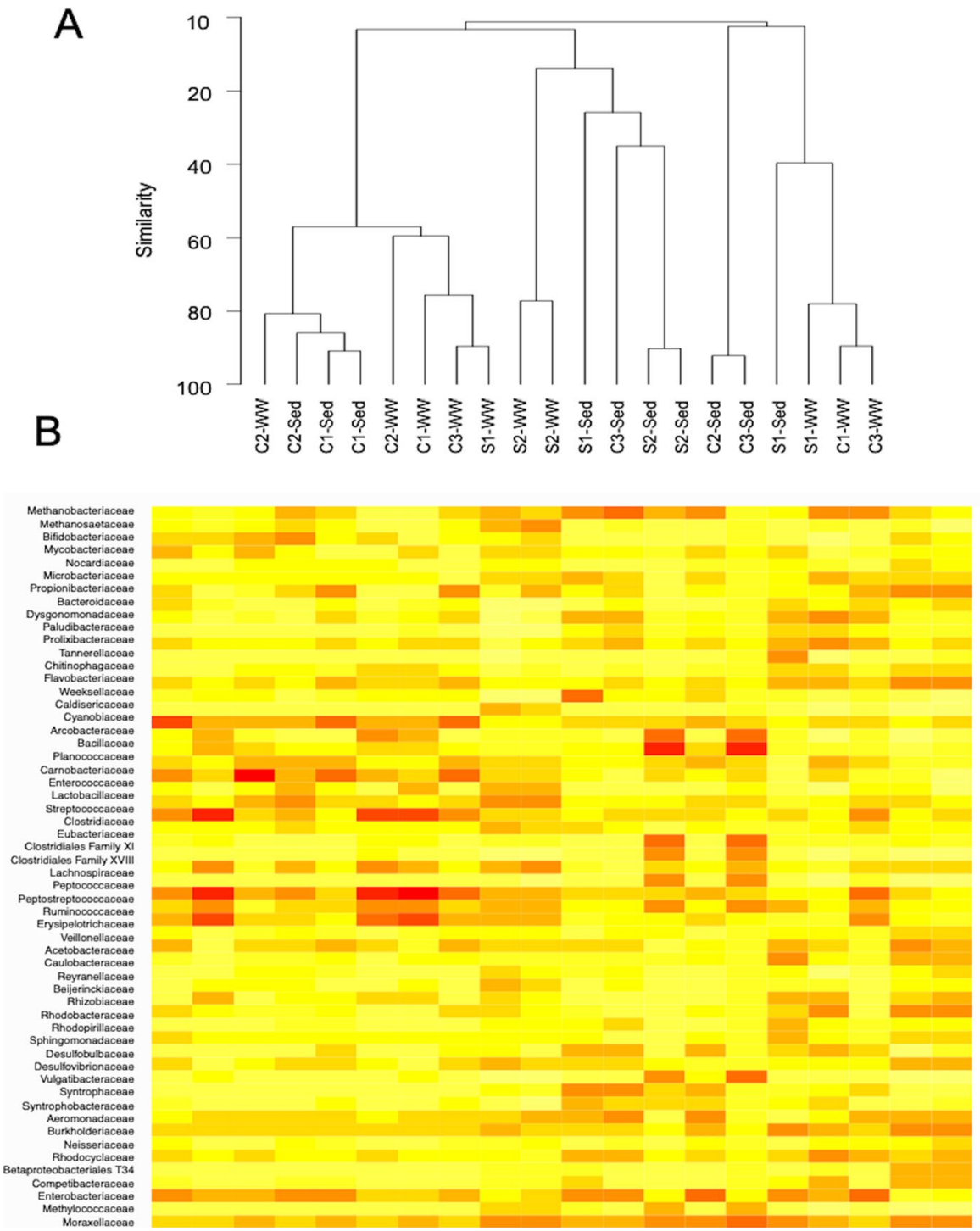

of antibiotic-resistant bacteria. Therefore, the use of metagenomic approaches to estimate abundance of antibiotic resistance bacteria in sewer systems will most likely result in overestimation of these cells. However, bacterial cells may not be transcribing the ARGs due to regulatory mechanisms that require the presence of the antibiotic molecule to promote gene expression [34, 35], or given the transient nature of mRNA, it is possible transcription was not captured at the time of sampling. Several studies have shown select antibiotics are present above the predicted minimum inhibition levels in sewage $[6,36,37]$. When these antibiotics are not present, gene expression would not be promoted, for example, for vanA that is regulated by a two-component system and ARGs that confer ribosomal protection such as some tet genes that are regulated by a repressor [34, 38]. This could explain why some ARG transcripts were undetected in the samples. Despite this limitation, here we demonstrated that mRNA RT-qPCR can be a suitable approach to quantify ARG transcripts in sewer sediment and wastewater samples.

Actively transcribed ARGs were more commonly detected in the sewer sediment samples relative to wastewater (Fig. 1). In contrast, in the previous genomic study, the six of the seven tested ARGs were present at a greater relative abundance in wastewater than the sewer sediments. Possible explanations for active transcription in the sewer sediment can be quorum sensing, presence on plasmids, or selective pressure. It has been proven that cell density can regulate the expression of multiple types of genes including ARGs [39]. Because in the sewer sediment matrix cells are mainly sessile growing attached to sediment, cell-to-cell interactions may be more likely to occur in comparison with the wastewater matrix, where cells are planktonic or attached to suspended solids. A previous study showed 
Fig. 4 Bar plots comparing the relative abundance of clinically relevant family taxa between the 16S rRNA and 16S rRNA gene microbiome analysis. Error bars represent the standard deviation $(\mathrm{n}=2)$

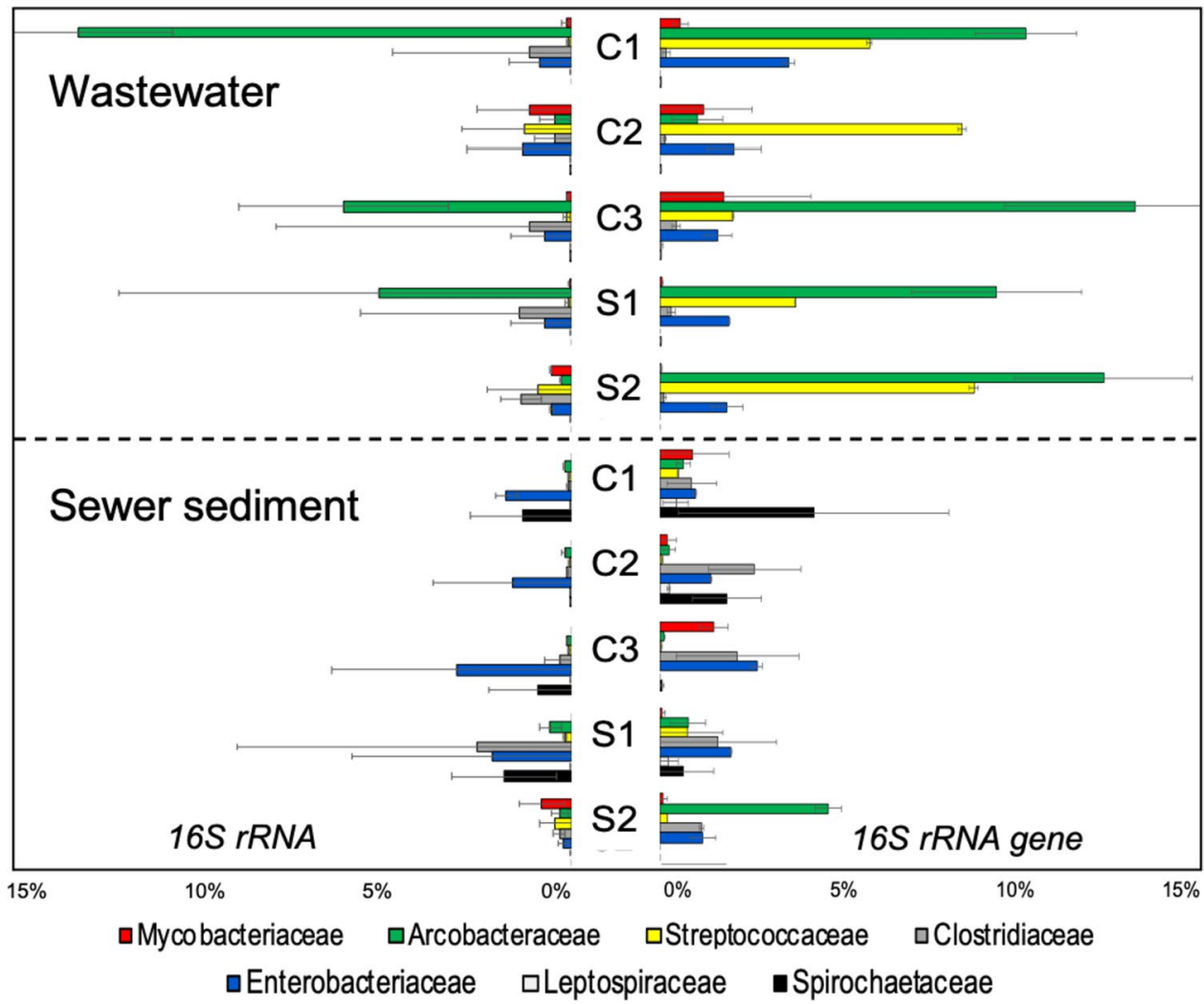

that the expression of the MexAB-OprM efflux pump ARG (note, $\operatorname{tet}(\mathrm{G})$ also encodes for an efflux pump) was positively regulated by quorum sensing in bacterial cells growing sessile in a culture media [40]. Another study showed that the PA1874-PA1877 drug efflux pump system had a tenfold higher gene expression when the cells were growing sessile in a biofilm under laboratory conditions compared to planktonic cells [41]. In addition, these three genes ( $s u l 1, b l a_{\mathrm{TEM}}$, and $\operatorname{tet}(\mathrm{G})$ ) have been identified in plasmids and mobile genetic elements including in wastewater samples [42-45], allowing for horizontal transfer, potentially increasing their abundance. However, other ARGs not detected in the transcripts that were highly abundant in the DNA, such as ermF, have been also found in transmissible mobile genetic elements in wastewater [45]. The presence of associated antibiotics in sewer systems could also impact gene expression. Monitoring for antibiotics was beyond the scope of this study, but other researchers have reported antibiotics above the predicted no-effect concentrations in wastewater [6] including tetracycline associated with $\operatorname{tet}(\mathrm{G})$ and penicillin (i.e., ampicillin and amoxicillin) associated with $b l a_{\text {TEM }}$ [6]. Hydrophobic antibiotics such as fluoroquinolones can accumulate in sewer sediments [36]. However, Jarnheimer et al.'s simulated sewer study did not associate an increase in the abundance of $q n r$ genes with sorption of fluroquinolones, but the impact on transcribed $q n r$ genes was not evaluated.

\section{Prokaryote Community Analysis: Comparison of $16 \mathrm{~S}$ rRNA and 16S rRNA Gene Sequencing}

The similarity in the prokaryotic community structure between the sewer types (combined vs. separate) may be due to the fact that all samples were collected during baseflow; therefore, the combined sewer wastewater was not diluted with stormwater. To our knowledge, no studies have assessed the prokaryote diversity of ribosomesynthesizing cells in sewer systems. Differences in the microbial community structure of wastewater, based on 16S rRNA gene vs.16S rRNA sequencing, suggest that 16S rRNA genes from non-metabolically active cells and/ or extracellular 16S rRNA genes may affect the wastewater microbiome analysis when relying only on DNAbased techniques. This observation is also consistent with previous microbiome studies of lake and tap water samples [10], and fluid samples from an oil production facility [46], where beta-diversity differed between $16 \mathrm{~S}$ rRNA gene and rRNA sequencing analysis. A likely reason for the differences in the microbial diversity results between rRNA gene and rRNA sequencing is the halflife of the DNA and RNA. In comparison to DNA, the half-life of RNA in the environment is much shorter [10]. A previous study on soil samples from alpine forests, alpine tundra, grasslands, and wetlands showed that in some soil ecosystems, extracellular DNA and DNA from 
dead cells can inflate the prokaryotic community richness and misestimate the relative abundances of bacterial taxa [47]. Another study in chlorinated wastewater effluent showed an average ratio of $\sim 0.3$ of $16 \mathrm{~S}$ rRNA genes from viable cells to $16 \mathrm{~S}$ rRNA genes from dead cells and extracellular DNA [3]; this is expected to be higher in untreated wastewater influent. This could explain why more sequences of some of the relevant taxa containing human pathogens were detected in the rRNA gene microbiome than in the rRNA transcript microbiomes (Fig. 4). The most notable example from this study is the family of Streptococcaceae, which had noticeably higher number of $16 \mathrm{~S}$ rRNA gene sequences relative to $16 \mathrm{~S}$ rRNA sequences in all wastewater samples $(p<0.041$, pairwise $t$ test). However, other family taxa showed RNA to DNA ratios above one, indicating a greater number of these sequences in the 16S rRNA than in the 16S rRNA gene analysis $(p<0.034$, pairwise $t$ test). A possible explanation for the discrepancy between the 16S rRNA and $16 \mathrm{~S}$ rRNA gene sequences from the same taxa can be due to the fact that rRNA concentration does not scale linearly with growth rate uniformly across taxa [14]. For example, in some Synechococcus spp. and Prochlorococcus spp., the rRNA concentration remains constant at low growth rate, and at intermediate growth rates, the rRNA concentration correlates linearly with growth rate, but at higher growth rates, the rRNA content decreases as growth increases [14, 48]. Another possible explanation for the discrepancy in number of sequences could be due to differences in recovery efficiencies between the two approaches (16S rRNA vs. 16S rRNA gene sequencing). Potential causes of differences in recovery could occur in the sample pre-processing: different nucleic acid extraction kits were used for each approach (FastDNA SPIN Kit for soil for 16S rRNA gene sequencing and RNeasy PowerSoil Total RNA Kit for 16S rRNA sequencing). Previous studies have reported differences in recovery efficiency from different nucleic acid extraction kits [49, 50]. Additionally, pre-processing of $16 \mathrm{~S}$ rRNA required a reverse transcription step, which can also affect the recovery efficiency [51].

Even though the use of $16 \mathrm{~S}$ rRNA sequencing has been proven to not correlate linearly with the abundance of some taxa in environmental samples [14], it is still a useful tool with which to study the metabolically active microbiome in environmental samples [10, 11, 14, 46]. Here we showed that $16 \mathrm{~S}$ rRNA sequencing can be performed with sewer sediment and wastewater samples to study the active microbiome in the sewer ecosystems. We also demonstrated that $16 \mathrm{~S}$ rRNA vs. 16S rRNA gene sequencing analysis of the sewer system microbiome may result in a different microbial community structure.

\section{Phylogenetic Analysis of Active Prokaryotes in Sewer Systems: Potential Human Pathogens and Corrosion-Causing Microbes}

Sequencing of the 16S rRNA showed the presence of some environmentally and clinically relevant taxonomical families. PCR targeting NTM showed that these bacteria were more commonly detected in wastewater than in sediment samples. NTM are known to be environmental bacteria with ubiquitous presence in water and soil [52]. They have been isolated from wastewater influent [52, 53] and from activated sludge [54] but their presence and occurrence in sewer sediments have not been evaluated. In contrast, sequences of other clinically relevant families like Spirochaetaceae were mainly found in the sediment matrix. Species of this family are also known to be one of the most abundant bacteria involved in sulfur oxidation in WWTPs [55]. Because the metabolism of sulfur is more associated with the sediment matrix due to the lower oxidation-reduction potential (ORP) [56], this could explain why the sequences of metabolically active Spirochaetaceae were more common in sediment samples. 16S rRNA sequences of hydrogenotrophic methanogenic Archaea were also found more commonly in the sediment matrix. These corrosion-causing microbes are strict anaerobes and are known to grow forming aggregates called granules with a hydrogen-producing syntrophic bacteria [57]. These granules have been widely isolated from sediment matrices including ocean sediment, lake sediment, and sewer sediments, which explains why sequences of this family taxa predominates in the sediment matrix [58]. In contrast to the methanogens, sequences of SRB families Desulfobulbaceae and Desulfovibrionaceae were detected in similar relative abundance in both matrices. Even though these SRB are obligate anaerobes like methanogens, they are better growing independently and taking up hydrogen from the environment, which allows them to develop ubiquitously [59] including in the wastewater matrix [60]. Of further interest for the sewer microbiome is these microbes' role in MIC. The US spent $\sim \$ 390$ billion in 20 years for the rehabilitation of concrete sewer structures [61]. Methanogens and sulfate-reducing bacteria are responsible for MIC of concrete and metal pipes [46, 61, 62]. A complementary $16 \mathrm{~S}$ rRNA and 16S rRNA gene microbiome study made on water and fluid samples from an oil production facility with corrosion issues showed higher sequence abundance of both methanogens and SRB in the rRNA community [46]. These observations and the fact that both methanogens and SRB were present metabolically active in all sewer samples suggest that $16 \mathrm{~S}$ rRNA microbiome analysis or complementary 16S rRNA and 16S rRNA gene sequencing analysis may provide more useful information for addressing MIC issues on sewer pipes than DNA techniques alone. 
The families Arcobacteraceae, Pseudomanadaceae, Streptococcaceae, Clostridiaceae, and Enterobacteriaceae were also detected as metabolically active in both matrices. Arcobacter spp., a genus in the Arcobacteraceae family, have been consistently detected in concentrations around $10^{6}$ cells per $\mathrm{mL}$ of wastewater $[63,64]$. This explains why this family was one of the most common taxa containing potential human pathogens in both $16 \mathrm{~S}$ rRNA and $16 \mathrm{~S}$ rRNA gene sequencing analyses. Enterobacteraceae and Streptococcaceae are family taxa containing potential pathogenic and fecal indicator bacteria and their sequences were also commonly found in both matrices (Fig. 4 and Fig. S3) [65, 66]. A compilation of the relative abundance of predominant family taxa in wastewater from multiple studies (based on $16 \mathrm{~S}$ rRNA gene amplicon and metagenome sequencing) showed that Enterobacteraceae and Streptococcaceae can compose $1.16 \%$ and $3.91 \%$ of the wastewater microbiome, respectively [63]. The presence of these taxa in the 16S rRNA analysis suggests that, as expected, fecal indicator bacteria persist and remain metabolically active in both wastewater and sewer sediment.

One noticeable result was the high number of sequences from metabolically active cells of the Pseudomonadaceae family ( $>50 \%$ in $8 / 20$ samples). Bacteria from this taxon are ubiquitous and have been isolated from both wastewater and sediments [67, 68]; however, the average reported relative abundance in sewage based on DNA amplicon sequencing was $2.38 \%$ [63]. In fact, in the present study, the average relative abundance of this same taxon based on 16S rRNA gene sequencing analysis was $0.75 \% \pm 0.53$. A possible explanation for the high number of $16 \mathrm{~S}$ rRNA sequences of the Pseudomonadaceae can be due to a non-scaled growth and rRNA concentration relationship as previously explained [14]. It has been reported that some bacterial species carry more rRNA copies in environments with high carbon availability, such as sewer systems, with the purpose of competing more efficiently when a substrate becomes available rather than for maintaining a high growth rate [69]. The phylogenetic analysis of the 16S rRNA sequences of this study along with the PCR targeting NTM demonstrated that pathogenic Mycobacterium spp. and other potential human pathogenic bacteria, and member of family taxa known to cause MIC, are present and metabolically active in sewer sediment and wastewater in both combined and separate sanitary sewer systems.

\section{Implications for Mobilization During Wet Weather Flows and Wastewater-Based Epidemiology}

The observations presented in this work have implications for understanding the hazards associated with sewer overflow as a function of sewer matrix. The wastewater and sewer sediments, studied here during baseflow conditions, can be released to surface waters during wet weather flows. Overflows that mobilize sediment in addition to wastewater would shift the active microbial hazard. Previous end-ofpipe studies of combined sewer overflow (CSO) outfalls demonstrated that attached and suspended microbes can be released at different times during storms [9]. This same research showed the presence of clinically relevant bacterial classes in CSOs including Clostridia, Bacteroidia, and Epsilonproteobacteria [9]; however, these data were obtained using DNA-based techniques. Results of the present study indicate that, if sewer sediment is released, more active pathogens in the Spirochaetaceae family will potentially be present, while pathogens from the Mycobacteraceae family could more likely be present when wastewater alone is released. These data can inform the design of treatment technologies that target different microbes.

The potential for shifts in the wastewater microbiome from metabolically active microbial community members and the decay of inactive members may be expected to be a function of hydraulic residence time and the kinetics of growth and decay. This could be accounted for during wastewater epidemiology studies if it were found to be sufficient to impact results of observations taken at different locations within the collection system. The shift in community structure from the fresh gut microbiome to wastewater [70, 71] indicates this may be possible. Of interest is the potential for sewers to serve as selective environments for growth of ARG-carrying microbes, selection, and/or horizonal gene transfer. Here we demonstrate expression of selected ARGs in sewer matrices.

\section{Conclusion}

mRNA analysis of the occurrence of ARGs in sewer sediment and wastewater provided insight in the abundance of functional ARGs in these matrices. $\operatorname{sul} 1, \operatorname{tet}(\mathrm{G})$, and $b l a_{\mathrm{TEM}}$ were transcribed ARGs, and their presence was more commonly observed in the sewer sediment matrix. Non-detection of mRNA sequences from some ARGs that were highly abundant in the previous DNA-based analysis [5] suggests that abundance of an ARG at the metagenomic level (total DNA) does not necessarily correlate with the abundance of the actively transcribed gene (mRNA). The use of mRNA RT-qPCR may be a useful tool to assess the antibiotic resistance transcriptome of sewer systems. 16S rRNA sequencing analysis resulted in a different community structure and diversity than in the $16 \mathrm{~S}$ rRNA gene microbial community analysis. Family taxa containing potential human pathogens and corrosion-causing bacteria were present and metabolically active in wastewater and sewer sediment samples in both combined and separate sanitary sewer systems. Overall, our results highlight the presence of cells with actively 
transcribed ARGs and metabolically active family taxa containing human pathogenic cells that would pose a hazard when released to the environment during sewer overflow events and may need to be accounted for in wastewater-based surveillance studies.

Supplementary Information The online version contains supplementary material available at https://doi.org/10.1007/s00248-021-01775-y.

Author Contribution WRMM - methodology, validation, formal analysis, investigation, data curation, writing — original draft, visualization; AE-methodology, validation, formal analysis, data curation, writing—original draft; NLF_conceptualization, writing—review and editing, supervision, project administration, funding acquisition.

Funding This work was supported by the National Science Foundation (Award \#1510461).

Data Availability All data generated or analyzed during this study are included in this published article (and its supplementary information files) and the NCBI Sequence Read Archive (SRA) PRJNA503259.

Code Availability Not applicable.

\section{Declarations}

Competing Interests The authors delcare no competing interests.

\section{References}

1. US Centers for Disease Control and Prevention (CDC) (2019) Antibiotic resistance threats in the United States. http://www.cdc. gov. Accessed March 2021

2. Morales Medina WR, Eramo A, Tu M, Fahrenfeld NL (2020) Sewer biofilm microbiome and antibiotic resistance genes as function of pipe material, source of microbes, and disinfection: field and laboratory studies. Environ Sci Water Res Technol 6(8):21222137. https://doi.org/10.1039/D0EW00265H

3. Eramo A, Morales Medina WR, Fahrenfeld NL (2019) Viabilitybased quantification of antibiotic resistance genes and human fecal markers in wastewater effluent and receiving waters. Sci Total Environ 656:495-502. https://doi.org/10.1016/j.scitotenv.2018. 11.325

4. Eramo A, Morales Medina WR, Fahrenfeld NL (2017) Peracetic acid disinfection kinetics for combined sewer overflows: indicator organisms, antibiotic resistance genes, and microbial community. Environ Sci Water Res Technol 3(6):1061-1072. https://doi.org/ 10.1039/c7ew00184c

5. Eramo A, Morales Medina WR, Fahrenfeld NL (2020) Factors associated with elevated levels of antibiotic resistance genes in sewer sediments and wastewater. Environ Sci Water Res Technol. https://doi.org/10.1039/D0EW00230E

6. Fahrenfeld N, Bisceglia KJ (2016) Emerging investigators series: sewer surveillance for monitoring antibiotic use and prevalence of antibiotic resistance: urban sewer epidemiology. Environ Sci Water Res Technol 2(5):788-799. https://doi.org/10.1039/C6EW0 $0158 \mathrm{~K}$

7. Auguet O, Pijuan M, Borrego CM, Rodriguez-Mozaz S, Triado-Margarit X, Giustina SVD, Gutierrez O (2017) Sewers as potential reservoirs of antibiotic resistance. Sci Total Environ 605-606:1047-1054. https://doi.org/10.1016/j.scitotenv.2017. 06.153

8. ten Veldhuis JA, Clemens FH, Sterk G, Berends BR (2010) Microbial risks associated with exposure to pathogens in contaminated urban flood water. Water Res 44(9):2910-2918. https://doi.org/10.1016/j.watres.2010.02.009

9. Eramo A, Delos Reyes H, Fahrenfeld NL (2017) Partitioning of antibiotic resistance genes and fecal indicators varies intra and inter-storm during combined sewer overflows. Front Microbiol 8:2024. https://doi.org/10.3389/fmicb.2017.02024

10. Li R, Tun HM, Jahan M, Zhang Z, Kumar A, Dilantha Fernando WG, Farenhorst A, Khafipour E (2017) Comparison of DNA-, PMA-, and RNA-based 16S rRNA Illumina sequencing for detection of live bacteria in water. Sci Rep 7(1):5752. https:// doi.org/10.1038/s41598-017-02516-3

11. Mills HJ, Martinez RJ, Story S, Sobecky PA (2005) Characterization of microbial community structure in Gulf of Mexico gas hydrates: comparative analysis of DNA- and RNA-derived clone libraries. Appl Environ Microbiol 71(6):3235-3247. https://doi. org/10.1128/AEM.71.6.3235-3247.2005

12. Schippers A, Neretin LN, Kallmeyer J, Ferdelman TG, Cragg BA, Parkes RJ, Jorgensen BB (2005) Prokaryotic cells of the deep sub-seafloor biosphere identified as living bacteria. Nature 433(7028):861-864. https://doi.org/10.1038/nature03302

13. Gentile G, Giuliano L, D'Auria G, Smedile F, Azzaro M, De Domenico M, Yakimov MM (2006) Study of bacterial communities in Antarctic coastal waters by a combination of $16 \mathrm{~S}$ rRNA and 16S rDNA sequencing. Environ microbiol 8(12):21502161. https://doi.org/10.1111/j.1462-2920.2006.01097.x

14. Blazewicz SJ, Barnard RL, Daly RA, Firestone MK (2013) Evaluating rRNA as an indicator of microbial activity in environmental communities: limitations and uses. ISME J 7(11):2061-2068. https://doi.org/10.1038/ismej.2013.102

15. Zhang DX, Tian K, Han LM, Wang QX, Liu YC, Tian CL, Liu MC (2014) Resistance to beta-lactam antibiotic may influence $n a n \mathrm{H}$ gene expression in Trueperella pyogenes isolated from bovine endometritis. Microb Pathog 71-72:20-24. https://doi. org/10.1016/j.micpath.2014.04.006

16. Dumas JL, van Delden C, Perron K, Kohler T (2006) Analysis of antibiotic resistance gene expression in Pseudomonas aeruginosa by quantitative real-time-PCR. FEMS Microbiol Lett 254(2):217-225. https://doi.org/10.1111/j.1574-6968.2005. 00008.x

17. Muyzer G, de Waal EC, Uitterlinden AG (1993) Profiling of complex microbial populations by denaturing gradient gel electrophoresis analysis of polymerase chain reaction-amplified genes coding for 16S rRNA. Appl Environ Microbiol 59(3):695-700

18. Pei R, Kim SC, Carlson KH, Pruden A (2006) Effect of river landscape on the sediment concentrations of antibiotics and corresponding antibiotic resistance genes (ARG). Water Res 40(12):2427-2435. https://doi.org/10.1016/j.watres.2006.04.017

19. Aminov RI, Chee-Sanford JC, Garrigues N, Teferedegne B, Krapac IJ, White BA, Mackie RI (2002) Development, validation, and application of PCR primers for detection of tetracycline efflux genes of gram-negative bacteria. Appl Environ Microbiol 68(4):1786-1793. https://doi.org/10.1128/aem.68.4.1786-1793. 2002

20. Aminov RI, Garrigues-Jeanjean N, Mackie RI (2001) Molecular ecology of tetracycline resistance: development and validation of primers for detection of tetracycline resistance genes encoding ribosomal protection proteins. Appl Environ Microbiol 67(1):2232. https://doi.org/10.1128/AEM.67.1.22-32.2001

21. Chen J, Yu Z, Michel FC Jr, Wittum T, Morrison M (2007) Development and application of real-time PCR assays for quantification of erm genes conferring resistance to 
macrolides-lincosamides-streptogramin B in livestock manure and manure management systems. Appl Environ Microbiol 73(14):4407-4416. https://doi.org/10.1128/AEM.02799-06

22. Diene SM, Bruder N, Raoult D, Rolain JM (2011) Real-time PCR assay allows detection of the New Delhi metallo-beta-lactamase (NDM-1)-encoding gene in France. Int J Antimicrob Agents 37(6):544-546. https://doi.org/10.1016/j.ijantimicag.2011.02.006

23. Dutka-Malen S, Evers S, Courvalin P (1995) Detection of glycopeptide resistance genotypes and identification to the species level of clinically relevant enterococci by PCR. J Clin Microbiol 33(1):24-27. https://doi.org/10.1128/JCM.33.1.24-27.1995

24. Narciso-da-Rocha C, Varela AR, Schwartz T, Nunes OC, Manaia CM (2014) bla $a_{\text {TEM }}$ and van A as indicator genes of antibiotic resistance contamination in a hospital-urban wastewater treatment plant system. J Global Antimicrob Resist 2(4):309-315. https:// doi.org/10.1016/j.jgar.2014.10.001

25. Radomski N, Roguet A, Lucas FS, Veyrier FJ, Cambau E, Accrombessi H, Moilleron R, Behr MA, Moulin L (2013) atpE gene as a new useful specific molecular target to quantify Mycobacterium in environmental samples. BMC Microbiol 13:277. https://doi.org/10.1186/1471-2180-13-277

26. Klindworth A, Pruesse E, Schweer T, Peplies J, Quast C, Horn M, Glockner FO (2013) Evaluation of general 16S ribosomal RNA gene PCR primers for classical and next-generation sequencingbased diversity studies. Nucleic Acids Res 41(1):e1. https://doi. org/10.1093/nar/gks808

27. Bolyen E, Rideout JR, Dillon MR, Bokulich NA, Abnet CC, AlGhalith GA, Alexander H, Alm EJ, Arumugam M, Asnicar F, Bai Y, Bisanz JE, Bittinger K, Brejnrod A, Brislawn CJ, Brown CT, Callahan BJ, Caraballo-Rodríguez AM, Chase J, Cope EK, Da Silva R, Diener C, Dorrestein PC, Douglas GM, Durall DM, Duvallet C, Edwardson CF, Ernst M, Estaki M, Fouquier J, Gauglitz JM, Gibbons SM, Gibson DL, Gonzalez A, Gorlick K, Guo J, Hillmann B, Holmes S, Holste H, Huttenhower C, Huttley GA, Janssen S, Jarmusch AK, Jiang L, Kaehler BD, Kang KB, Keefe CR, Keim P, Kelley ST, Knights D, Koester I, Kosciolek T, Kreps J, Langille MGI, Lee J, Ley R, Liu Y-X, Loftfield E, Lozupone C, Maher M, Marotz C, Martin BD, McDonald D, McIver LJ, Melnik AV, Metcalf JL, Morgan SC, Morton JT, Naimey AT, Navas-Molina JA, Nothias LF, Orchanian SB, Pearson T, Peoples SL, Petras D, Preuss ML, Pruesse E, Rasmussen LB, Rivers A, Robeson MS, Rosenthal P, Segata N, Shaffer M, Shiffer A, Sinha R, Song SJ, Spear JR, Swafford AD, Thompson LR, Torres PJ, Trinh P, Tripathi A, Turnbaugh PJ, Ul-Hasan S, van der Hooft JJJ, Vargas F, Vázquez-Baeza Y, Vogtmann E, von Hippel M, Walters W, Wan Y, Wang M, Warren J, Weber KC, Williamson CHD, Willis AD, Xu ZZ, Zaneveld JR, Zhang Y, Zhu Q, Knight R, Caporaso JG (2019) Reproducible, interactive, scalable and extensible microbiome data science using QIIME 2. Nat Biotechnol 37(8):852-857. https://doi.org/10.1038/s41587-019-0209-9

28. Payne RB, Ghosh U, May HD, Marshall CW, Sowers KR (2019) A pilot-scale field study: in situ treatment of PCB-impacted sediments with bioamended activated carbon. Environ Sci Technol 53(5):2626-2634. https://doi.org/10.1021/acs.est.8b05019

29. Team RC (2018) R: a language and environment for statistical computing. R Foundation for Statistical Computing, Vienna

30. Jari Oksanen FGB, Friendly M, Kindt R, Legendre P, Dan, McGlinn PRM, O'Hara RB, Simpson GL, Solymos P, Henry MH, Stevens ESaHW (2019) Vegan: community ecology package. R package version 2.5-6. https://CRAN.R-project.org/package=vegan. Accessed March 2021

31. Arbizu PM (2019) pairwiseAdonis: pairwise multilevel comparison using adonis. R packege version 0.3 edn. https://github.com/ pmartinezarbizu/pairwiseAdonis

32. Laht M, Karkman A, Voolaid V, Ritz C, Tenson T, Virta M, Kisand V (2014) Abundances of tetracycline, sulphonamide and beta-lactam antibiotic resistance genes in conventional wastewater treatment plants (WWTPs) with different waste load. PLoS ONE 9(8):e103705. https://doi.org/10.1371/journal.pone.0103705

33. Xu J, Xu Y, Wang H, Guo C, Qiu H, He Y, Zhang Y, Li X, Meng W (2015) Occurrence of antibiotics and antibiotic resistance genes in a sewage treatment plant and its effluent-receiving river. Chemosphere 119:1379-1385. https://doi.org/10.1016/j.chemosphere.2014.02.040

34. Dar D, Sorek R (2017) Regulation of antibiotic-resistance by non-coding RNAs in bacteria. Curr Opin Microbiol 36:111-117. https://doi.org/10.1016/j.mib.2017.02.005

35. Alekshun MN, Levy SB (2007) Molecular mechanisms of antibacterial multidrug resistance. Cell 128(6):1037-1050. https:// doi.org/10.1016/j.cell.2007.03.004

36. Jarnheimer PA, Ottoson J, Lindberg R, Stenstrom TA, Johansson M, Tysklind M, Winner MM, Olsen B (2004) Fluoroquinolone antibiotics in a hospital sewage line; occurrence, distribution and impact on bacterial resistance. Scand J Infect Dis 36(10):752-755. https://doi.org/10.1080/00365540410021027

37. Carballa M, Omil F, Lema JM (2008) Comparison of predicted and measured concentrations of selected pharmaceuticals, fragrances and hormones in Spanish sewage. Chemosphere 72(8):1118-1123. https://doi.org/10.1016/j.chemosphere.2008.04.034

38. Berens C, Hillen W (2003) Gene regulation by tetracyclines. Constraints of resistance regulation in bacteria shape TetR for application in eukaryotes. Eur J Biochem 270(15):3109-3121. https://doi. org/10.1046/j.1432-1033.2003.03694.x

39. Zhao X, Yu Z, Ding T (2020) Quorum-sensing regulation of antimicrobial resistance in bacteria. Microorganism 8(3). https://doi. org/10.3390/microorganisms8030425

40. Maseda H, Sawada I, Saito K, Uchiyama H, Nakae T, Nomura N (2004) Enhancement of the mexAB-oprM efflux pump expression by a quorum-sensing autoinducer and its cancellation by a regulator, MexT, of the mexEF-oprN efflux pump operon in Pseudomonas aeruginosa. Antimicrob Agents Chemother 48(4):1320 1328. https://doi.org/10.1128/aac.48.4.1320-1328.2004

41. Zhang L, Mah TF (2008) Involvement of a novel efflux system in biofilm-specific resistance to antibiotics. J Bacteriol 190(13):4447-4452. https://doi.org/10.1128/JB.01655-07

42. Zhang T, Zhang XX, Ye L (2011) Plasmid metagenome reveals high levels of antibiotic resistance genes and mobile genetic elements in activated sludge. PLoS ONE 6(10):e26041. https://doi. org/10.1371/journal.pone.0026041

43. Jiang H, Cheng H, Liang Y, Yu S, Yu T, Fang J, Zhu C (2019) Diverse mobile genetic elements and conjugal transferability of sulfonamide resistance genes (sul1, sul2, and sul3) in Escherichia coli isolates from Penaeus vannamei and pork from large markets in Zhejiang. China Front Microbiol 10:1787. https://doi.org/10. 3389/fmicb.2019.01787

44. Muhammad I, Golparian D, Dillon JA, Johansson A, Ohnishi M, Sethi S, Chen SC, Nakayama S, Sundqvist M, Bala M, Unemo M (2014) Characterisation of $b l a_{\text {TEM }}$ genes and types of betalactamase plasmids in Neisseria gonorrhoeae-the prevalent and conserved $b l a_{\text {TEM-135 }}$ has not recently evolved and existed in the Toronto plasmid from the origin. BMC Infect Dis 14:454. https:// doi.org/10.1186/1471-2334-14-454

45. Che Y, Xia Y, Liu L, Li AD, Yang Y, Zhang T (2019) Mobile antibiotic resistome in wastewater treatment plants revealed by Nanopore metagenomic sequencing. Microbiome 7(1):44. https:// doi.org/10.1186/s40168-019-0663-0

46. Salgar-Chaparro SJ, Machuca LL (2019) Complementary DNA/ RNA-based profiling: characterization of corrosive microbial communities and their functional profiles in an oil production facility. Front Microbiol 10:2587. https://doi.org/10.3389/fmicb.2019.02587

47. Carini P, Marsden PJ, Leff JW, Morgan EE, Strickland MS, Fierer N (2016) Relic DNA is abundant in soil and obscures estimates of 
soil microbial diversity. Nat Microbiol 2:16242. https://doi.org/ 10.1038/nmicrobiol.2016.242

48. Worden AZ, Chisholm SW, Binder BJ (2000) In situ hybridization of Prochlorococcus and Synechococcus (marine cyanobacteria) spp. with rRNA-targeted peptide nucleic acid probes. Appl Environ Microbiol 66(1):284-289. https://doi.org/10.1128/aem.66.1. 284-289.2000

49. Santos HF, Carmo FL, Leite DC, Jesus HE, Maalouf Pde C, Almeida C, Soriano AU, Altomari D, Suhett L, Volaro V, Valoni E, Francisco M, Vieira J, Rocha R, Sardinha BL, Mendes LB, Joao RR, Lacava B, Jesus RF, Sebastian GV, Pessoa A, van Elsas JD, Rezende RP, Pires DO, Duarte G, Castro CB, Rosado AS, Peixoto RS (2012) Comparison of different protocols for the extraction of microbial DNA from reef corals. Braz J Microbiol 43(2):517-527. https://doi.org/10.1590/S1517-83822012000200012

50. Read SJ (2001) Recovery efficiences on nucleic acid extraction kits as measured by quantitative LightCycler PCR. Mol Pathol 54(2):86-90. https://doi.org/10.1136/mp.54.2.86

51. Minshall N, Git A (2020) Enzyme- and gene-specific biases in reverse transcription of RNA raise concerns for evaluating gene expression. Sci Rep 10(1):8151. https://doi.org/10.1038/ s41598-020-65005-0

52. Amha YM, Anwar MZ, Kumaraswamy R, Henschel A, Ahmad F (2017) Mycobacteria in municipal wastewater treatment and reuse: microbial diversity for screening the occurrence of clinically and environmentally relevant species in arid regions. Environ Sci Technol 51(5):3048-3056. https://doi.org/10.1021/acs.est. $6 \mathrm{~b} 05580$

53. Whan L, Ball HJ, Grant IR, Rowe MT (2005) Occurrence of Mycobacterium avium subsp. paratuberculosis in untreated water in Northern Ireland. Appl Environ Microbiol 71(11):7107-7112. https://doi.org/10.1128/AEM.71.11.7107-7112.2005

54. Radomski N, Betelli L, Moilleron R, Haenn S, Moulin L, Cambau E, Rocher V, Goncalves A, Lucas FS (2011) Mycobacterium behavior in wastewater treatment plant, a bacterial model distinct from Escherichia coli and Enterococci. Environ Sci Technol 45(12):5380-5386. https://doi.org/10.1021/es104084c

55. Meyer DD, de Andrade PA, Durrer A, Andreote FD, Corcao G, Brandelli A (2016) Bacterial communities involved in sulfur transformations in wastewater treatment plants. Appl Microbiol Biotechnol 100(23):10125-10135. https://doi.org/10.1007/ s00253-016-7839-3

56. Liu Y, Tugtas AE, Sharma KR, Ni BJ, Yuan Z (2016) Sulfide and methane production in sewer sediments: field survey and model evaluation. Water Res 89:142-150. https://doi.org/10.1016/j. watres.2015.11.050

57. Schink B (1997) Energetics of syntrophic cooperation in methanogenic degradation. Microbiol Mol Biol Rev 61(2):262-280

58. Trego AC, O'Sullivan S, Quince C, Mills S, Ijaz UZ, Collins G (2020) Size shapes the active microbiome of methanogenic granules, corroborating a biofilm life cycle. mSystems 5(5). https:// doi.org/10.1128/mSystems.00323-20
59. Oremland RS, Polcin S (1982) Methanogenesis and sulfate reduction: competitive and noncompetitive substrates in estuarine sediments. Appl Environ Microbiol 44(6):1270-1276. https://doi.org/ 10.1128/AEM.44.6.1270-1276.1982

60. Hao OJ, Chen JM, Huang L, Buglass RL (1996) Sulfate-reducing bacteria. Crit Rev Environ Sci Technol 26(2):155-187. https://doi. org/10.1080/10643389609388489

61. Wang T, Wu K, Kan L, Wu M (2020) Current understanding on microbiologically induced corrosion of concrete in sewer structures: a review of the evaluation methods and mitigation measures. Constr Build Mater 247:118539. https://doi.org/10.1016/j.conbu ildmat.2020.118539

62. Enning D, Garrelfs J (2014) Corrosion of iron by sulfate-reducing bacteria: new views of an old problem. Appl Environ Microbiol 80(4):1226-1236. https://doi.org/10.1128/AEM.02848-13

63. McLellan SL, Roguet A (2019) The unexpected habitat in sewer pipes for the propagation of microbial communities and their imprint on urban waters. Curr Opin Biotechnol 57:34-41. https:// doi.org/10.1016/j.copbio.2018.12.010

64. Fisher JC, Levican A, Figueras MJ, McLellan SL (2014) Population dynamics and ecology of Arcobacter in sewage. Front Microbiol 5:525. https://doi.org/10.3389/fmicb.2014.00525

65. McLellan SL, Newton RJ, Vandewalle JL, Shanks OC, Huse SM, Eren AM, Sogin ML (2013) Sewage reflects the distribution of human faecal Lachnospiraceae. Environ Microbiol 15(8):22132227. https://doi.org/10.1111/1462-2920.12092

66. US Environmental Protection Agency (2012) Recreational water quality criteria. Office of Water Report: 820-F-12-058

67. Al-Jebouri MM (1985) A note on antibiotic resistance in the bacterial flora of raw sewage and sewage-polluted River Tigris in Mosul. Iraq J Appl Bacteriol 58(4):401-406. https://doi.org/10. 1111/j.1365-2672.1985.tb01479.x

68. Roosa S, Wauven CV, Billon G, Matthijs S, Wattiez R, Gillan DC (2014) The Pseudomonas community in metal-contaminated sediments as revealed by quantitative PCR: a link with metal bioavailability. Res Microbiol 165(8):647-656. https://doi.org/10. 1016/j.resmic.2014.07.011

69. Binnerup SJ, Bloem J, Hansen BM, Wolters W, Veninga M, Hansen M (2001) Ribosomal RNA content in microcolony forming soil bacteria measured by quantitative $16 \mathrm{~S}$ rRNA hybridization and image analysis. FEMS Microbiol Ecol 37(3):231-237. https://doi.org/10.1111/j.1574-6941.2001.tb00870.x

70. Newton RJ, McLellan SL, Dila DK, Vineis JH, Morrison HG, Eren AM, Sogin ML (2015) Sewage reflects the microbiomes of human populations. mBio 6(2):e02574. https://doi.org/10.1128/ mBio.02574-14

71. Cai L, Ju F, Zhang T (2014) Tracking human sewage microbiome in a municipal wastewater treatment plant. Appl Microbiol Biotechnol 98(7):3317-3326. https://doi.org/10.1007/ s00253-013-5402-z 